\title{
INFÂNCIA E EDUCAÇÃO EM DE PUERIS DE ERASMO DE ROTTERDAN
}

\section{CHILDHOOD AND EDUCATION IN DE PUERIS BY ERASMUS OF ROTTERDAM}

\author{
Márcio Danelon* \\ Marco Aurélio Gomes de Oliveira** \\ Solange Richter"
}

\begin{abstract}
Resumo: O presente texto tem por objetivo fazer uma reflexão sobre a imagem de infância tal como ela aparece em De Pueris, de Erasmo de Rotterdan. Como esse filósofo não criou, efetivamente, uma concepção de infância, queremos resgatar, na obra mencionada, a imagem de infância e sua relação com a educação. Nesse caso, observaremos que a função da educação na infância é instituir a racionalidade na criança, como um processo de humanização e substancialização do infante. Para isso, faremos uma breve contextualização histórica do renascimento, dando destaque para o aspecto pedagógico desse período. A partir da concepção antropológica de Erasmo, que parte da premissa de que o homem não nasce homem, mas transforma-se em homem, observaremos que é pela educação da criança que se faz esse homem. É pela educação, portanto, que se potencializa a substância racional da criança. Assim, o homem será o produto da educação que recebeu na infância.
\end{abstract}

Palavras-chave: Educação. Infância. Erasmo.

Abstract: The present text aims to reflect about the concept of childhood in De pueris, by Erasmus of Rotterdam. As this philosopher did not define a concept of childhood, this article aims to analyze in De pueris the image of childhood and its relation with education. It is observed that the function of education in childhood is to develop rationality in the child, as a process of humanization and substantiation of the infant. To this end, a brief historical contextualization of renaissance is presented, emphasizing the pedagogical aspect of that period. Based on Erasmus's anthropological concept who believed that man is not born a man but becomes a man, it is observed that it is through education that a child becomes a man. It is through education that the rational substance of the child is developed. Thus, a man will be the product of the education he received during his childhood.

Keywords: Education. Childhood. Erasmus of Rotterdam.

\footnotetext{
* Professor Adjunto da Faculdade de Educação da Universidade Federal de Uberlândia. Doutor em Educação. E-mail: <danelon@faced.ufu.br>.

* Doctor in Education. Professor at the Education College at the Federal University of Uberlândia. E-mail: <danelon@faced.ufu.br>.

** Universidade Federal de Uberlândia. Mestre em Educação. E-mail: <marcoaurelioufu@yahoo.com.br>

${ }^{* *}$ Universidade Federal de Uberlândia. Master in Education. E-mail: <marcoaurelioufu@yahoo.com.br>

***Graduada em Pedagogia. Universidade Federal de Uberlândia. E-mail: <solangeufu@yahoo.com.br>

*** Undergraduate student of Pedagogy.Fedeal University of Uberlândia. E-mail: <solangeufu@yahoo.com.br>.
} 


\section{Introdução}

O momento histórico conhecido como renascimento, ocorrido na Europa a partir de meados do século $\mathrm{XV}$, foi arquitetado por uma série de mudanças sociais, econômicas, culturais e políticas. Além do caráter social, a filosofia também influenciou esse momento, na medida em que postulava um novo lugar para o homem no universo, atribuindo um valor totalmente renovado da dimensão racional do homem.

A modernidade é um período em que o homem busca respostas para a sua existência, de modo a superar o paradigma cristão, isto é, a existência das coisas e dos homens vinculada a um ser divino, que, por sua vez, era detentor da verdade universal das coisas. Dessa forma, a modernidade operou várias revoluções em diferentes campos, dentre os quais: geográfico, econômico, político, social, ideológico, cultural e pedagógico.

Dentre essas mudanças que desencadearam o processo de modernização, daremos destaque ao aspecto pedagógico que contribuiu para o entendimento do problema proposto nesta comunicação, que é a construção da imagem de infância dessa época, especificamente, a partir do humanismo renascentista de Erasmo.

Na modernidade operou-se uma transformação da mentalidade do homem quanto ao estatuto da racionalidade. Se, no medievo, a razão foi, num primeiro momento, a instância que desvirtua e afasta o homem em relação ao divino, condensada na premissa “Creio porque é absurdo”, e, posteriormente, esteve a serviço do divino, ou seja, a razão era um instrumento de Deus, condensada na premissa "Creio para compreender", a modernidade se inaugura com um novo paradigma para a razão. Esta, agora, deveria se preocupar com a existência concreta e material do homem. Trata-se de uma razão a serviço da dimensão temporal e não somente com o divino. Segundo Cambi (2001), no âmbito ideológico-cultural,

[...] a modernidade opera uma dupla transformação: primeiro, de laicização, emancipando a mentalidade [...] da visão religiosa do mundo e da vida humana e ligando o homem à história e à direção de seu processo (a liberdade, o progresso); segundo, de racionalização, produzindo uma revolução profunda nos saberes que se legitimam e se organizam através de um livre uso da razão. (CAMBI, 2001, p. 198).

É desse novo estatuto da razão que advieram as grandes navegações, o renascimento das grandes cidades, o nascimento das ciências da natureza, o surgimento do estado moderno, dentre outras transformações. A educação também foi “contagiada” por esse novo estatuto da razão, materializada pelo advento da instituição escolar laica.

Nesse cenário, tais mudanças possibilitaram ao homem uma liberdade perante si mesmo e as coisas, uma vez que nesse momento ele se reconhece como um sujeito histórico, isto é, que busca por meio de seus pensamentos e suas ações as condições necessárias para a mudança de sua realidade social. É importante lembrar que antes, diante de uma concepção teocêntrica de mundo, não lhe era possível mudar, transformar essa realidade. Assim, a função do homem alterou-se a partir das transformações econômicas, culturais e sociais ocorridas na Europa no período renascentista. Nesse caso, o homem renascentista passou a preocupar-se com a organização de sua vida, libertando-se das amarras controladoras da igreja. Dessa forma, é o homem o comandante da sua vida, tal qual propunha a cultura renascentista.

Nesse contexto de desenvolvimento econômico e social, observamos o advento 
de um movimento que exerceu influência decisiva no período renascentista: o movimento humanista (DELUMEAU, 1984). Devemos lembrar que esse movimento foi o responsável pelo surgimento de um novo modelo de homem, tanto na filosofia quanto nas artes renascentistas. Cabe apontar, também, que Erasmo foi contemporâneo desse movimento, na medida em que esses ideais de homem livre e autônomo estavam presentes em seu pensamento.

O movimento humanista é particularmente interessante de se observar neste contexto de caracterização do início da modernidade. Ele nasceu dentro das universidades medievais no século XV como oposição a um modelo de estudo universitário permeado pela cultura da igreja, que se fundamentava, basicamente, no estudo do direito, da medicina e, principalmente, da teologia, conhecido como trivium.

Esse modelo de estudo medieval tinha por objetivo propagar o ideal hierárquico da igreja, sua visão dogmática de conhecimento e uma postura puramente contemplativa do homem e da natureza. Contudo, as mudanças econômicas e sociais ocorridas na Europa nesse período caminhavam de encontro ao estado estático e contemplativo proposto pela igreja, na medida em que o homem do renascimento é um homem de ação na transformação da sociedade de seu tempo.

Dessa forma, as transformações sociais vinham na contramão do ideal humano católico, mas, por outro lado, ao encontro da concepção humanista de homem, que, assim, veio corromper os alicerces de sustentação do ideal cristão, propondo um homem que deveria valorizar seu corpo, pois era dotado de beleza; deveria investir em sua racionalidade, pois ela era capaz de produzir conhecimento livre; deveria transformar a natureza para satisfazer seus desejos.
Os humanistas idealizavam uma transformação e revitalização dos estudos tradicionais, propondo os chamados estudos humanos: poesia, filosofia, história, matemática, retórica e artes. Essa nova grade de estudos para as universidades era indissociável do aprendizado das línguas clássicas: latim e grego. Assim, o estudo dos textos propostos pelos humanistas concentrava-se em textos de autores clássicos, daí o fato de esse movimento ter voltado à cultura clássica, pois, para eles, a fase mais expressiva e perfeita da cultura ocorreu no período pré-cristão.

Os valores propagados pelos humanistas exaltavam o indivíduo, seus feitos, sua capacidade de ação, sua liberdade empreendedora e sua autonomia. Tais valores caíam bem ao gosto das transformações sociais renascentistas, pois o homem deixa de ser passivo e contemplativo para ser ativo e transformador em suas ações. Os humanistas acreditavam que os homens eram fontes de criatividade, que, somadas à sua capacidade de agir, traziam um novo modelo de vida que engrandecia o ser humano e a sua cultura.

Diante de uma nova realidade vivenciada pelo homem, com novos preceitos ideológicos e culturais, foi necessário que se pensasse um novo modelo de educação. No que tange ao aspecto pedagógico, mudaram, segundo Cambi (2001),

[...] os fins da educação, destinando-se esta a um indivíduo ativo na sociedade, liberado de vínculos e de ordens, posto como artifex fortunae suae e do mundo em que vive; um indivíduo mundanizado, nutrido de fé laica e aberto para o cálculo racional da ação e suas conseqüências [...] a pedagogia-educação se renova, delineando-se como saber e como práxis, para responder de forma nova àquela passagem do mundo tradicional para o mundo moderno. (CAMBI, 2001, p. 199). 
Através dessas mudanças o homem passa a ter uma centralidade, um estatuto de sujeito situado num mundo de transformações que ele mesmo opera. Uma nova ordem social, política, econômica e epistemológica está por ser construída pelo sujeito moderno. A educação, nesse cenário, também se transforma. Não mais como produto exclusivo da Igreja Católica, a educação transcende esse vinculo com a instituição religiosa e como instrumento do divino, cujo último produto, naquela época, foi o modelo de educação jesuítica.

Assim, na modernidade começou o questionamento sobre qual deveria ser o ponto de partida para uma educação que contemplasse os anseios dessa nova ordem social e desse novo sujeito nascente. É nesse período que as atenções se voltam para a infância e a criança, pois se acreditava que nessa fase da vida humana o indivíduo se apresenta propenso para iniciar o processo de aprendizagem, isto é, por meio da educação esse indivíduo é formado para viver de acordo com as regras e valores legitimados pela sociedade.

\section{A imagem da infância no humanismo de Erasmo de Rotterdan}

Em A história social da criança e da família, de Philippe Ariès (1981), defende-se a tese de que desde a antiguidade até o período medieval, e ainda no humanismo, não havia no mundo ocidental um sentimento de infância, ou seja, não havia uma reflexão em torno da infância como um problema. Nesse caso, a infância não era entendida como um período específico da vida, portanto, com necessidades singulares e modos de vida próprios. Herdeiro de uma perspectiva desde a Grécia Clássica, o medievo tomava a criança como um ser fraturado em sua constituição humana, ou seja, a humanidade da criança ainda the é ausente nessa fase da vida.

Conforme Kohan (2003), tanto em Platão como em Aristóteles o cenário que se tece em volta da criança é o de um ser destituído da substância humana, ou seja, o logos, discurso racional. Aristóteles, em Ética a Nicômaco, compara as crianças aos seres mais baixos da polis: "Da mesma forma as crianças, devido ao crescimento, estão em condições comparáveis às dos ébrios [...]". (ARISTÓTELES, 1999, 1154b). Porque é destituída das crianças a racionalidade em ato, elas vivem à margem do exercício da cidadania, à margem da política, como os vândalos, os escravos e as mulheres.

No caso de Aristóteles, a racionalidade configura-se como uma potência que a criança traz em si. É pela educação que essa potência pode se atualizar, transformando-se em ato. Em Platão, a mesma imagem de criança é retratada principalmente em $A$ República e, posteriormente, em as Leis. Em A República, encontramos a seguinte afirmação bastante reveladora: "É claro que também descobrirás nela, em grande número e feitio, paixões, prazeres e dores, sobretudo nas crianças, nos escravos e na turba de homens de baixa condição [...]”. (PLATÃO, 1997, p. 129).

Em Infância: entre a educação e a filosofia, Kohan apresenta quatro imagens de infância que aparecem em Platão. Para ele, Platão caracteriza a criança como um ser marcado pela incapacidade, pela menoridade, pela dependência e pela possibilidade (KOHAN, 2003, p. 16-24). Assim, porque na infância, segundo Platão, não há o logos, ela é marcada pela incapacidade do raciocínio e dos juízos lógicos, pela menoridade no exercício político, pela dependência em relação ao adulto na condução de sua vida e, finalmente, porque a criança é marcada pela negatividade (não é racional), guarda a 
possibilidade de se constituir como cidadã. É aqui, como também em Aristóteles, que a educação tem o papel de formação do cidadão, do habitante da polis.

No período medieval, a imagem da infância ainda continua pintada com traços escuros. Com a introdução da noção de pecado, o período da infância é marcado pela queda constante no pecado. Como a criança ainda não possui a racionalidade, lhe é facultada a incapacidade de contemplação do divino. Nas Confissões, Santo Agostinho retrata a infância como portadora da maldade e do pecado:

Assim, a debilidade dos membros infantis é inocente, mas não a alma das crianças. Vi e observei uma, cheia de inveja, que ainda não falava e já olhava pálida, de rosto colérico, para o irmãozinho. Quem não é testemunha do que eu afirmo? Diz-se até que as mães e as amas procuram esconjurar este defeito, não sei com que prática supersticiosa. (AGOSTINHO, 1973, p. 30-31)

A despeito da tese defendida por Áries, emergem diversas contestações, como, por exemplo, as de Kohan (2003), Corazza (2000), e Agamben (2005), principalmente sobre a tese da inexistência de uma reflexão mais sistematizada sobre a infância até a modernidade. Não queremos discutir a pertinência ou não do texto de Áries, que já é um clássico e, portanto, é fundamental para qualquer reflexão sobre a temática da infância. Apenas sublinhamos que, a despeito da contenda se existe ou não uma reflexão sobre a infância anterior ao século XVII, o pensamento filosófico, desde a Grécia Clássica, produziu algum tipo de reflexão sobre a infância, principalmente no campo da Antropologia Filosófica. De fato, é somente em Rousseau, especificamente no Emílio, que se desenvolve, a partir da filosofia, uma reflexão mais apurada sobre a infância.
Não obstante todo o debate subjacente à temática da infância, queremos tomar esse momento da existência humana como um problema bastante profícuo para a modernidade. O renascimento, ao re-colocar o homem no centro do mundo, produziu saberes sobre as mais diversas dimensões do homem e, entre elas, a infância ocupou um lugar importante, conforme a afirmação de Araújo:

Portanto, desde o período do Renascimento nascem e desenvolvem outras formas de explicação, outras maneiras de explicar a vida humana, para a existência, para a educação. Então, é aí que a criança e a infância se tornam centrais, posto que essa fase da vida é primordial às outras fases. Tal concepção traz desdobramentos: trata-se de compreender melhor a criança, de compreender o seu mundo infantil, suas características para melhor educá-la. Por isso, a criança é concebida como um indivíduo que tem especificidades, que pode ser desenvolvido, que pode ser formado, que pode ser educado. Veja-se então que falar de criança e infância está muito ligado à maneira como se deve educá-la. (ARAÚJO, 2004, p. 12).

Para nossa compreensão nesta comunicação a respeito das concepções de infância na Modernidade nos propomos a estudar o filósofo Erasmo de Rotterdan ${ }^{1}$ (1469-1536), mais especificamente sua obra intitulada $D e$ Pueris - A civilidade Pueril, na qual retrata sua visão de mundo, de homem, de educação, de infância e de criança.

\footnotetext{
${ }^{1}$ Erasmo de Rotterdan nasceu em outubro de 1469, na cidade de Roterdã, Holanda. Foi criado em meio a uma cultura religiosa católica e também educado em escolas de cunho religioso, entra estas, a escola secundarista dos Frades Franciscanos, e mais tarde entra para a ordem dos Agostinianos. Em 1516, deixa o celibato sacerdotal por consentimento do Papa Leão X. Erasmo veio a falecer em 12 de julho de 1536, na cidade de Basiléia, Suíça.
} 
Erasmo considera que a educação é o meio pelo qual o indivíduo realiza sua humanidade, pois o homem não nasce completo, mas sim com uma natureza racional que se caracteriza pelas potencialidades a serem desenvolvidas. Cabe, portanto, ao processo educativo o papel de formação dos valores éticos e morais do indivíduo. Com a premissa de que o homem não nasce homem, mas transforma-se, a educação vem atualizar essa potencialidade do homem como um ser dotado, em substância, de racionalidade. Erasmo entende a natureza humana como composta por três etapas. A educação deve, então, realizar essa natureza humana que é tripla: natureza individual, natureza da espécie e natureza como objetivo da educação.

Para Erasmo, a educação como condição necessária para a humanização, como condição para o progresso rumo à civilização, deve atuar na criança em sua dimensão física, na medida em que ela deve promover a liberdade da criança em relação aos seus instintos primitivos, aos desejos e impulsos físicos.

Segundo Erasmo, enquanto a dimensão instintiva bestial do homem não estiver disciplinada pela educação, a criança permanecerá escrava desses impulsos e, portanto, marginalizada da civilização. A educação deve atuar, também, na dimensão dos sentimentos, através da educação estética com as obras de arte, com o objetivo de desenvolver na criança o sentimento de amor mútuo na sociedade, que é de fundamental importância para a evolução rumo ao homem civilizado.

A terceira dimensão humana em que a educação deve atuar rumo ao ideal humano é a do intelecto, no sentido de que uma pessoa desprovida de inteligência é presa das opiniões, ideologias e dogmatismo. Para Erasmo, uma criança que permanece em tal estado de alienação e cegueira jamais poderá desenvolver suas potencialidades humanas, que lhe permitirão o desfrute promissor do convívio social.

Refletindo à luz do referencial teórico da Grécia clássica, Erasmo concebe o homem, especificamente na idade infantil, como negatividade, pois não atua a partir de juízos lógico/racionais. A natureza individual é concebida, por sua vez, como bipartida, ou seja, como ser dócil e violento. Para Erasmo, as crianças possuem uma natureza que é extremamente receptiva ao processo educativo e aos valores da civilidade cortês, mas possui também uma natureza que é resistente à educação e aos valores que regulam a vida coletiva.

Em suma, os indivíduos estão voltados conjuntamente para a bestialidade instintiva dos desejos imediatos e na direção do desenvolvimento dos valores da humanidade. Para Erasmo, as crianças possuem qualidades individuais que refletem nossa natureza resistente ou receptiva à educação, sendo necessário, então, desenvolver exatamente essas qualidades para trazer à luz aquilo que a criança é. Dessa forma, é pelo processo educativo que emergirão as potencialidades que todos nós carregamos em nossa natureza.

Nesse caso, torna-se papel da educação efetivar essa passagem para a humanidade como realização da racionalidade. Como produto da educação, o homem se faz pela bestialidade numa má educação, ou se faz pela perfeição numa boa educação. O modo de distanciar a criança da dimensão bestial e aproximar da condição da civilidade consiste no desenvolver a razão na criança. Se instituir é desenvolver o homem na criança, esse homem se faz necessariamente com a razão. Assim, a educação, para Erasmo, tem por objetivo último desenvolver a razão, que é pré-requisito para o convívio coletivo na civilização.

Dessa forma, a educação como processo de instituição do homem na criança 
aparece sempre como a marca indispensável pela qual as crianças são arrancadas de seu estado instintivo, bestial, e direcionadas para um ideal de ser humano que se caracteriza, sempre, como um ser inteligente, cortês, polido, educado, que vive segundo as regras da convivência civilizada, conforme Erasmo explicita em A civilidade pueril:

A arte de instruir crianças consta de diversas etapas. A primeira e a principal consiste em fazer com que o espírito ainda tenro receba as sementes da piedade; a segunda, que tome amor pelas belas artes e as aprenda bem; a terceira que seja iniciada nos deveres da vida; a quarta, que se habitue, desde cedo, com as regras da civilidade. (ERASMO, 1999, p. 10).

Para a realização da substancialidade humana, Erasmo defende a ideia de que a educação deve começar na mais tenra idade, pois é nesse período que o indivíduo está propenso a receber a moldura que define sua humanidade, ou seja, a razão. Nessa fase, de fato, a criança necessita de instrução para deixar de lado seus comportamentos viris e animalescos. Segundo Erasmo, a falta de instrução leva a criança a assimilar mais os maus comportamentos em contrapartida dos bons comportamentos:

Apenas sobre um ponto advertiria com atrevimento, talvez, mas, por certo, movido pela benquerença: não te amoldes à opinião e ao exemplo muito em voga, deixando decorrerem os primeiros anos do teu filho sem tirar proveito algum da instrução. Faze-o aprender as primeiras noções antes que a idade fique menos dúctil e o animo mais propenso aos defeitos ou até mesmo infestado com as raízes de vícios tenacíssimos. (ERASMO, s/d, p. 21).

A concepção de infância defendida por Erasmo é a de um ser em estado de vir-a-ser, isto é, a criança possui uma natureza racional que deve ser formada com o auxílio dos agentes educativos, dentre os quais se destacam os pais e o preceptor. Esses agentes educativos terão a função de trabalhar as potencialidades das crianças, as quais podem pender para o mal ou para o bem, refletindo-se nas relações sociais entre os indivíduos:

A natureza, quando te dá um filho, ela não
te outorga nada além de uma massa infor-
me. A ti cabe o dever de moldar até a per-
feição, em todos os detalhes, aquela ma-
téria flexível e maleável. Se não levares a
cabo a tarefa terás uma fera. Ao contrário,
se lhe deres a assistência, terás, diria eu,
uma divindade. [...] Manuseia a cera en-
quanto mole. Modela a argila enquanto
úmida. Enche o vaso de bons licores en-
quanto novo. Tinge a lã quando sai nívea
do pisoeiro e ainda isenta de manchas.
(ERASMO, s/d, p. 33).

A partir de tal citação, podemos entender a criança, vista por esse autor, no primeiro momento, como uma criatura que só se realizará enquanto potencialidade humana mediante a instituição da racionalidade e, também, pela interação com outros homens, os quais, imbuídos do mecanismo da educação, mediam o processo de humanização da infância.

Vale ressaltar que, para Erasmo, devemos ter o cuidado de não sobrecarregarmos as crianças com tarefas que exigem um esforço para além de sua capacidade naquele momento, pois poderíamos causar nelas um desconforto e sentimento de frustração por não realizarem tais atividades. O autor afirma que a educação deve ser algo agradável, isto é, mesmo sendo rigorosa e disciplinar, ela deve ser prazerosa tanto para quem aprende quanto para quem ensina. Portanto, para Erasmo (s/d), 
Os anos de infância são como a primavera ridente em branda vegetação que se transforma em plantas de alegre viço com a chegada outonal dos anos viris, quando os celeiros transbordam de frutas sazonadas. Tal como seria descabido procurar uvas maduras durante a primavera, ou rosas no outono, assim incumbe ao preceptor atentar para o que convém a cada idade. À criança se ofertam sempre coisas alegres e amenas. Em qualquer hipótese, que fique longe da escola toda espécie de amargura e violência. (ERASMO, s/d, p. 92).

Sobretudo, o autor enfatiza que a educação deve ser iniciada na mais tenra idade. A relevância de tal premissa fundamenta-se na perspectiva erasmiana de que o homem nasce incompleto, insensato e inacabado; e, nesse sentido, está inclinado a uma aprendizagem de hábitos viciosos. Conforme suas palavras, a educação tem por função emancipar o indivíduo de sua condição primitiva:

Até o agricultor menos avisado não deixa parte nenhuma de seu campo ficar de todo em abandono. Na parte menos própria ao plantio de trigo ou nela cultiva outras plantas ou forma pastagens ou ocupa de legumes. E nós? Vamos tolerar que a parte mais promissora da vida fique deserta de floração erudita? Terra arada, de recente, se não for povoada de qualquer plantação, por si mesma produz cizânia. $\mathrm{O}$ mesmo sucede com a mente infantil. Não sendo, logo de principio, de ensinamentos frutíferos, cobre-se de vícios. (ERASMO, s/d, p. 101).

Segundo Erasmo, a infância é o momento crucial para formação do indivíduo, visto que a criança não tem suas concepções, suas crenças, seus valores e hábitos desenvolvidos. Assim, em contradição com a concepção de educação e infância na Idade Medieval, em que a criança deveria ser afastada de seus pais para não receber influências que comprometessem seu desenvolvimento natural, para Erasmo os pais assumem um papel fundamental na iniciação da instrução dos filhos. Vale destacar aqui a ruptura erasmiana com uma longa tradição de silenciamento da infância.

Apesar de ainda tomar a criança como um adulto em miniatura, portanto, sem necessidades e especificidades singulares, tal qual na Idade Média, Erasmo instaura a necessidade de que a educação se inicie já na mais tenra idade, e também de se assumir a criança como um ser cujos pais não devem se furtar da tarefa de educar. Em De Pueris (p. 87), Erasmo tece severas críticas aos pais que gastam mais tempo e dinheiro com o cuidado dos cavalos, por exemplo, do que com a educação dos filhos.

Para Erasmo, não se trata mais do processo de isolamento da criança junto às amas de leite, como era frequente até então, mas da necessidade de os pais tomarem a formação da criança como uma tarefa importante. Assim, tornar-se uma besta ou um homem brilhante está intimamente ligado ao processo educativo desde os pais até o preceptor.

Nesse cenário, caberia aos pais a função primeira de serem exemplo de boa conduta para os filhos, uma vez que as crianças utilizam-se muito da imitação para aprender determinados comportamentos. Dessa forma, os primeiros educadores de boas maneiras das crianças seriam seus próprios pais, pois, segundo Erasmo (s/d, p. 38), "a natureza premia, de modo peculiar, a criança com a facilidade para a imitação, mas, por vezes, aquele pendor volta-se mais para o mal do que para o bem”.

Uma segunda função dos pais para com a educação seria a escolha do preceptor de seus filhos, sendo que tal escolha deveria ser feita o quanto antes, para se poder conhecer melhor aquele a quem seria confiada a 
educação das crianças. Esse educador, por sua vez, deveria manter uma conduta exemplar, de

[...] um homem de bons costumes e de caráter meigo, dotado de conhecimentos invulgares, a cujo regaço possas confiar teu filho como ao nutriz de seu espírito a fim de que, a par do leite sorva o néctar das letras e, assim condividas, por igual, os cuidados entre as amas e o preceptor de sorte que aquelas lhe fortificam o pequeno corpo com o melhor dos sucos enquanto este zela pela mente, subministrando ensinamentos salutares e honestos. (ERASMO, s/d, p. 22).

\section{Considerações finais}

Em síntese, podemos concluir que a concepção erasmiana de infância supera a visão até então presente na sociedade, advinda do período medieval, que considerava a criança como um ser cujo desenvolvimento se daria de forma natural, cabendo ao educador apenas a função de facilitador desse desenvolvimento. Já para Erasmo, tanto os pais quanto os preceptores desempenham um papel de suma importância para a aprendizagem e desenvolvimento do infante, pois é por meio da educação que este se torna homem.

Assim, para esse filósofo a educação é algo central na vida da sociedade, pois a má educação compromete o desenvolvimento proposto segundo os preceitos renascentistas e modernistas, os quais preconizam a historicidade do homem, tendo, portanto, em suas mãos o poder de mantê-la ou transformá-la de acordo com seus interesses políticos, econômicos e culturais.

\section{Referências}

AGAMBEN, G. Infância e história. Belo Horizonte: Editora da UFMG, 2005.

AGOSTINHO. De magistro. São Paulo: Abril Cultural, 1973.

ARAUJO, J. C. de S. Marcos filosóficos da modernidade em torno da educação da criança: antropologia da infância em disputa? In: ENCONTRO DE PEDAGOGIA. AS IMAGENS DA INFÂNCIA NO BRASIL: TENDÊNCIAS E PERSPECTIVAS, 4. Anais... Patos de Minas: Centro Universitário de Patos de Minas, 2004.

ÁRIES, P. História social da criança e da família. Rio de Janeiro: LTC, 1981.

ARISTÓTELES. Ética a Nicômaco. Brasília: Editora da UnB, 1999.

CAMBI, F. História da pedagogia. São Paulo: Editora UNESP, 2001.

CORAZZA, S. História da infância sem fim. Ijuí: Editora da UNIJUÍ, 2000.

DELUMEAU, J. A civilização do renascimento. Lisboa: Editorial Estampa. V. 2, 1984.

ERASMO. A civilidade pueril. Revista Intermeio, n. 2, UFMS, 1999.

ERASMO. De pueris. São Paulo: Ed. Escala. [19?]

KOHAN, W. Infância: entre educação e filosofia. Rio de Janeiro: Autêntica, 2003.

PLATÃO. A república. São Paulo: Abril Cultural, 1997.

Recebido em: 29/02/2012

Aceito em: 21/05/2012 